\title{
Dietary Lignan and Proanthocyanidin Consumption and Colorectal Adenoma Recurrence in the Polyp Prevention Trial
}

\author{
Gerd Bobe ${ }^{1,2}$, Gwen Murphy ${ }^{3}$, Paul S. Albert ${ }^{4}$, Leah B. Sansbury ${ }^{5}$, Elaine Lanza ${ }^{1}$, Arthur \\ Schatzkin ${ }^{3}$, and Amanda J. Cross ${ }^{3}$ \\ ${ }^{1}$ Laboratory of Cancer Prevention, Center for Cancer Research, National Cancer Institute (NCI), \\ National Institutes of Health (NIH), Department of Health and Human Services (DHHS), \\ Frederick, MD 21702, USA \\ ${ }^{2}$ Linus Pauling Institute and Department of Animal Sciences, Oregon State University, Corvallis, \\ OR 97333, USA \\ ${ }^{3}$ Nutritional Epidemiology Branch, Division of Cancer Epidemiology and Genetics (DCEG), NCl, \\ $\mathrm{NIH}$, DHHS, 6120 Executive Blvd., Rockville, MD 20852, USA \\ ${ }^{4}$ Biostatistics and Bioinformatics Branch, National Institute of Child Health and Human \\ Development, NIH, DHHS, 6100 Executive Blvd., Rockville, MD 20852, USA \\ ${ }^{5}$ Epidemiology and Genetics Research Program, Division of Cancer Control and Population \\ Science, NCI, NIH, DHHS, 6130 Executive Blvd., Rockville, MD 20852, USA
}

\section{Abstract}

Lignans and proanthocyanidins are plant polyphenols that have shown protective properties against colorectal neoplasms in some human studies. Using logistic regression, we estimated odds ratios (ORs) and 95\% confidence intervals (CIs) to prospectively evaluate the association between lignan and proanthocyanidin intake, estimated from databases linked to a food frequency questionnaire, and adenoma recurrence in 1,859 participants of the Polyp Prevention Trial. Overall, individual or total lignans or proanthocyanidins were not associated with colorectal adenoma recurrence. However, in sex-specific analyses, total lignan intake was positively associated with any adenoma recurrence in women (highest versus lowest lignan intake quartile $\mathrm{OR}=2.07,95 \%$ CI: $1.22-3.52, P$ trend $=0.004)$ but not in men $(P$ interaction $=0.04)$. To conclude, dietary lignan and proanthocyanidin consumption was not generally related to colorectal adenoma recurrence; however, high lignan intake may increase the risk of adenoma recurrence in women.

\section{Keywords}

cancer prevention; colorectal adenoma; colorectal cancer; lignans; proanthocyanidins

\section{Introduction}

Polyphenols have generated interest as components of fruits and vegetables that show cancer protective properties ${ }^{1,2}$. Based on their chemical structure, polyphenols are divided into

Correspondence and current affiliation: Gerd Bobe, 112 Withycombe Hall, Oregon State University, Corvallis, OR 97331; gerd.bobe@oregonstate.edu; phone: 541-737- 1898; fax: 541-737-4174.

Conflict of Interest: None

Conflict of interest The authors declare no conflict of interest. 
subclasses, the most pertinent being tannins (proanthocyanidins, hydrolysable tannins), lignans, stilbenes, phenolic acids, and flavonoids ${ }^{3}$. We previously showed that the flavonoid subgroups flavonols and isoflavonoids and the flavan-3-ol epigallocatechin-3-gallate (EGCG) decrease the risk of advanced adenoma recurrence in the Polyp Prevention Trial (PPT) ${ }^{4,5}$.

Lignans are diphenolic compounds present in the fibrous portion of plants, which are (partially or fully) converted by microbial gut flora to enterolactone and enterodiol ${ }^{6}$. The richest dietary sources of lignans are flax or linseed and sesame seed $(3.5 \mathrm{~g} / \mathrm{kg})^{7}$. Beverages (wine, tea, coffee, orange juice), cereals, bread, legumes, fruits (strawberries, peaches, oranges), and vegetables (broccoli; squash, cabbage) are, despite having 100-1,000 fold lower lignan contents than flax or sesame seed, the major dietary sources of lignans ${ }^{8-11}$. The antioxidative, anti-inflammatory, and phytoestrogenic properties of lignans and their metabolites, as well as their ability to inhibit proliferation, invasion, and angiogenesis and to promote apoptosis ${ }^{12-17}$ suggest a plausible role for them in chemoprevention of colorectal carcinogenesis. Results from human studies are mixed with lignan consumption being associated with increased risk of colorectal cancer in a Canadian case-control study but a decreased risk in an English nested case-control study ${ }^{1118}$. The association between lignan intake and colorectal cancer may differ between men and women, as sex modified the association between enterolactone concentrations and colorectal cancer in both a Danish and an English nested case-control study ${ }^{18,19}$. Dietary fibre and fat may modify the association between lignan intake and colorectal cancer by altering the intestinal microflora and, thus, the conversion of plant lignans to the more bioactive enterolactone and enterodiol ${ }^{20}$; as such, lignan intake and enterolactone concentration produced opposing results in relation to colorectal cancer in the English nested case-control study ${ }^{18}$. Furthermore, dietary lipids may alter the effect of lignans on the metabolism of steroid hormones 6,21 , which are involved in the etiology of colorectal tumorigenesis, as lignans and lipids are both involved in steroid hormone synthesis and metabolism.

Proanthocyanidins (e.g., condensed tannins) are polymers of elementary flavan-3-ol units and are common constituents of U.S. diets $22-24$. The main dietary sources of proanthocyanidins are fruits (grapes, apples, plums), legumes (dry beans), beverages (red wine, tea, cocoa, fruit juices), and chocolate $23,25,26$. Their antioxidant, anti-mutagenic, anti-inflammatory, and antimicrobial activity, along with their ability to chelate metal ions, proteins, and toxins, promote apoptosis and inhibit proliferation supports their role in chemoprevention of colorectal cancer in animal and in vitro studies $22,27,28$. The results from human studies, however, are less convincing: a Scottish and an Italian case-control study reported an inverse association between proanthocyanidin intake and colorectal cancer risk 29,30; whereas another Scottish case-control study, as well as the prospective Iowa Women's Health Study reported no association with colorectal cancer ${ }^{31,32}$.

The objective of our study was to prospectively evaluate whether consumption of lignans and proanthocyandins, overall or stratified by gender and key dietary factors, was associated with colorectal adenoma recurrence in the PPT. To our knowledge, this is the first study to prospectively evaluate this relationship.

\section{Materials and Methods}

\section{Study design and population}

The PPT was a 4-year randomized, multi-center, nutritional intervention trial to evaluate whether an intervention designed to encourage consumption of a high-fibre, high-fruit and high-vegetable, and low-fat diet would decrease the risk of adenoma recurrence. Details of the study have been previously described ${ }^{33-35}$. To be eligible for the study, participants had 
at least one histologically-confirmed colorectal adenoma identified by complete colonoscopy in the 6 months before study entry. Our study included 1,859 participants of the control $(\mathrm{n}=930)$ and the intervention arm $(\mathrm{n}=929)$ that had a colonoscopy at baseline $(\mathrm{T} 0)$ and at the end of the four year trial (T4), as well as dietary data for any of the first 3 years of the study (T1, T2, or T3). The institutional review boards of the National Cancer Institute and each participating center approved the study and all participants provided written informed consent.

\section{Adenoma assessment}

At baseline (T0), one year later (T1), and four years after baseline (T4), participants had a full colonoscopy. Participants that missed the T1 colonscopy (8.2\%) had a full colonscopy by the end of year T2. The first two colonoscopies were clearing colonoscopies used to remove any existing adenomas, while the T4 colonoscopy and any unscheduled colonoscopy after year 2 (1.31 colonoscopies per participant after year 2) was used to determine adenoma recurrence. All colorectal lesions were evaluated for histologic features, size, and degree of atypia by two independent pathologists. Adenomas detected after year 2 were considered recurrent adenomas. Adenomas that were at least $1 \mathrm{~cm}$ in size, had at least $25 \%$ villous components, or showed high grade dysplasia were classified as advanced adenomas. High risk adenoma recurrence was defined as having at least 3 pathologically confirmed adenomas of any size or an advanced adenoma at $\mathrm{T} 4$.

\section{Lignan and proanthocyanidin data}

At T0 and at each of the annual follow-up visits, participants completed a self-administered modified Block-National Cancer Institute Food Frequency Questionnaire (FFQ), which asked about the frequency of intake and portion size of 119 food and beverage items during the past year ${ }^{34,35}$. Some FFQ food items were a single fruit or vegetable, such as apples, while others were grouped food items, such as 'other fruits', which included grapes, plums, and pineapples. Trained, certified nutritionists reviewed all FFQs with participants ${ }^{36}$. Compared with 24-hour dietary recalls and four-day food record data, the FFQ slightly overestimated fat and underestimated fibre, fruit $\&$ vegetable intake and had acceptable correlations for fat $(r=0.63)$, fibre $(r=0.63)$, fruit \& vegetable $(r=0.72)$, dry bean $(r=$ 0.76 ), and other macro- and micro-nutrients. With respect to foods with available lignan data, the FFQ asked 3 questions on legumes, 1 on nuts, 17 on vegetables (including soups), 11 on fruits, 9 on breads/cereals, 13 on beverages, and 11 on processed food consumption. The FFQ did not specifically ask questions on intakes of flaxseed, linseed, or sesame seed, which are enriched in lignans, because these were rarely consumed in the U.S. when the PPT was conducted. Lignan intake was estimated for 58 of 65 food and beverage items using a Canadian phytoestrogen database and was calculated as the sum of lariciresinol, matairesinol, pinoresinol, and secoisolariciresinol ${ }^{8}$. Three other phytoestrogen databases 10,37, 38 were used for 7 food items (brown or wild rice, brussel sprouts, chocolate candy, other vegetables, peas, popcorn, spaghetti) not included in the Canadian database. The four databases were similar in lignan concentrations of common foods and beverages. With respect to foods with available proanthocyanidin data, the FFQ asked 11 questions on fruits, 21 on vegetables (including soups), 12 on beverages (including beer, fruit juices, tea, and wine), and 1 on chocolate consumption. Proanthocyanidin intake was estimated from the 2004 U.S. Department of Agriculture (USDA) comprehensive proanthocyanidin database ${ }^{26}$ that reviewed, evaluated, and summarized the existing proanthocyanidin databases and calculated the sum of monomers, dimers, trimers, 4-6 mers, 7-10 mers, and polymers (>10 flavan-3-ol units). The FFQ was not specifically validated for lignan and proanthocyanidin intake using 24-hour dietary recalls and four-day food record data. Lignan and proanthocyanidin intake from dietary supplements was not included because the intake 
of supplements containing significant amounts of lignans and proanthocyanidins was low in the PPT.

\section{Lifestyle data}

Besides the FFQ completed at $\mathrm{T} 0$ and the annual follow-up visits, participants also completed an interviewer-administered questionnaire about demographics (including age, gender, and education level), physical activity, smoking (including intensity and duration of smoking), family history of cancer (including number of first-degree relatives with cancer), clinical visits, and medication and supplement use (including name, dosage, and frequency of use). Regular non-steroidal anti-inflammatory drug (NSAID) use was defined as taking aspirin or non-aspirin NSAIDs such as ibuprofen, naproxen, indomethacin, or piroxicam at least once per month. Hormone replacement therapy among women was defined as taking either unopposed estrogens or estrogen/progestin combinations. Physical activity was defined as self-reported time typically spent for any type of moderate or vigorous physical activity, including both occupational and non-occupational activities.

\section{Statistical analyses}

Statistical analyses were performed using SAS, version 9.1 (SAS, Inc., Cary, NC, U.S.) software. Baseline participant characteristics and dietary intakes of lignans, proanthocyanidins, and primary dietary sources of lignans and proanthocyanidins [at $\mathrm{T} 0$, and during the first 3 years of the trial (mean of T1, T2, T3)] were evaluated by adenoma recurrence at T4 (any or high risk adenoma recurrence versus no recurrence) using Wilcoxon rank sum test for continuous variables and Fisher's exact test for categorical variables. Dietary data from T4 was not used because it was collected after colonoscopy (used for assessing adenoma recurrence) in some participants. Spearman's and Pearson's correlation coefficients between lignans, proanthocyanidins, and primary dietary sources of lignans and proanthocyanidins were calculated.

The association between dietary intakes of lignans and proanthocyanidins [T0 (not shown in Tables) and mean of T1, T2, and T3 (shown in the Tables)] and colorectal adenoma recurrence was evaluated by odds ratios (ORs) and 95\% confidence intervals (95\% CI) using multivariate logistic regression. A linear trend test was performed using the ln-transformed median value of each dietary intake quantile as a continuous variable in a logistic regression model. Participants characteristics, listed in Table 1, were evaluated as potential confounders by adding them in a stepwise manner to the model. Potential confounders remained in the model if they changed the association by $>10 \%$, had a $\chi^{2} P$-value $\leq 0.20$, and were associated with both adenoma recurrence and lignan or proanthocyanidin intake. Saturated fat intake was a confounder for the association between proanthocyanidin consumption and adenoma recurrence but not for the association between lignan consumption and adenoma recurrence. Two multivariate logistic regression models are shown: a) crude analysis [age quartiles, sex, and energy intake (continuous) during the first 3 trial years] and b) multivariate analysis [age quartiles, sex, BMI, NSAID use at baseline, energy intake (continuous) and saturated fat intake (quartiles, only for proanthocyanidins) during the first 3 trial years].

To evaluate the statistical power to see a biologically meaningful effect of lignan and proanthocyanidin consumption on any or advanced adenoma recurrence, we used Monte Carlo simulation of 2,000 computer-generated datasets with the sample size of the trial (464 individuals in each of the four quartiles) and a true relationship described by an OR of 0.88 , 0.79 , and 0.70 in the second, third, and fourth quartiles (relative to the first quartile) and computed the proportion that were statistically significant at the 0.05 significance level (with a two-sided trend test). Age, gender, BMI, regular NSAID use, and dietary fat intake [the 
available variables were total fat, total saturated fat, oleic acid, linoleic acid, and saturation index (proportion of saturated fatty acids on total fatty acids)] were evaluated for effect modification. For continuous variables, the median values were used as cutoffs $(\leq$ median, $>$ median). The interaction $p$-value for the stratified data was calculated from the interaction term between the $\ln$-transformed median value of each dietary intake quartile as a continuous variable and the categorical variable evaluated for effect modification. All $p$ values were considered statistically significant at either $P \leq 0.05$, or after adjusting for multiple comparisons using the Bonferroni correction at $P \leq 0.008$.

\section{Results}

At the end of the 4-year trial, $40 \%$ of participants had at least 1 recurrent adenoma, $12 \%$ had high risk adenoma, and 7\% had an advanced adenoma recurrence (Table 1). Adenoma recurrence was more common in men and older individuals, and less common in women who used hormone therapy. In addition, advanced adenoma recurrence was more common in individuals that did not regularly use NSAIDs (Table 1). Intake of lignans and proanthocyanidins was log-normally distributed and, therefore, is shown as median and quartile intakes (Table 1). At baseline, lignan and proanthocyanidin consumption as a percentage of total energy intake was higher in females than males (both $P<0.0001$ ).

Compared to baseline, total daily lignan consumption increased on average from 135 to 167 $\mu \mathrm{g}$ during the first three years of the trial $(P<0.0001)$, those in the intervention arm increased lignan consumption by $67 \pm 3 \mu \mathrm{g} / \mathrm{d}(P<0.0001$; in comparison to the control group: $+3 \pm 2 \mu \mathrm{g} / \mathrm{d} ; P=0.002$ ). The major dietary sources of lignans during the PPT ( $\geq 5 \%$ of total lignan intake) were whole grain rice or pasta (15\%), broccoli (9\%), coffee (8\%), and spaghetti with tomato sauce (6\%). The primary sources of lariciresinol, matairesinol, pinoresinol, and secoisolariciresinol were broccoli (26\%), whole grain rice or pasta (68\%), tea $(14 \%)$, and whole grain rice or pasta (14\%), respectively. Except for broccoli (11.6 versus $12.5 \mathrm{~g} / \mathrm{d}$ for those with any versus no adenoma recurrence; $P=0.01$ ), intake of major sources of lignans did not vary by adenoma recurrence status (data not shown). Total proanthocyanidin intake increased from 111 to $154 \mathrm{mg} / \mathrm{d}$ from baseline during the first three years of the trial $(P<0.0001)$, as the intervention group increased their proanthocyanidin intake by $81 \pm 3 \mathrm{mg} / \mathrm{d}(P<0.0001$; in comparison to the control group: $+0.7 \pm 2 \mathrm{mg} / \mathrm{d} ; P=$ 0.05 ). The primary dietary sources of proanthocyanidins during the PPT ( $\geq 5 \%$ of total intake) were apples (30.2\%), other fruits (grapes, plums, pineapples: $17.3 \%$ ), chocolate $(14.1 \%)$, tea $(9.3 \%)$, and dry beans $(8.7 \%)$. Of the major dietary proanthocyanidin sources, individuals with high risk adenoma recurrence had lower tea intake than those with no adenoma recurrence (5.93 versus $12.9 \mathrm{~g} / \mathrm{d})$ and lower dry bean intake (11.3 versus $15.4 \mathrm{~g} / \mathrm{d}$ ).

Our power calculation revealed that we had $99 \%$ and $96 \%$ power to detect OR of $0.88,0.79$, and 0.70 in the second, third and fourth quartiles (relative to the first quartile) for any recurrence and for an advanced recurrence, respectively. Overall, consumption of total or individual lignans during the first 3 years of the trial was not associated with adenoma recurrence (Table 2); adjusting for dietary fibre, which was closely correlated with lignan consumption during the trial $(\mathrm{r}=0.77)$, or saturated fat intake did not alter these association (results not shown). Similarly, consumption of proanthocyanidins, overall or for polymers of varying length, was not associated with adenoma recurrence (Table 3); adjusting for saturated fat intake, which may affect microbial proanthocyanidin metabolism in the small intestine, but not dietary fibre, which was also correlated with lignan consumption during the trial $(r=0.71)$ did alter these associations.

After stratification by gender, total lignan intake during the first 3 trial years was positively associated with any adenoma recurrence in women (highest versus lowest lignan intake 
quartile $\mathrm{OR}=2.07,95 \% \mathrm{CI}: 1.22-3.52, P$ trend $=0.004)$, but not in men $(\mathrm{OR}=0.91,95 \% \mathrm{CI}$ $=0.64-1.30 ; P$ interaction $=0.04 ;$ Table 4$)$. Total T0 lignan intake, change in lignan intake from baseline, and fibre consumption were not associated with any adenoma recurrence in women or men (results not shown). Total proanthocyanidin intake was positively associated with high risk adenoma recurrence in men $(\mathrm{OR}=2.00,95 \% \mathrm{CI}=1.08-3.70, P$ trend $=0.02)$, but no significant interaction was noted between gender and proanthocyanidin intake $(P$ interaction $=0.34)($ Table 4$)$. Stratification by age, BMI, or regular NSAID use did not reveal any other associations between consumption of lignans and proanthocyanidins and adenoma recurrence (data not shown).

For those individuals consuming the median or below median intake of saturated fat during the trial, lignan intake was positively associated with any $(\mathrm{OR}=1.94,95 \% \mathrm{CI}=1.17-3.19$, $P$ trend $=0.009)$ and high risk adenoma recurrence $(\mathrm{OR}=3.21,95 \% \mathrm{CI}=1.36-7.59, P$ trend $=0.008)$ (Table 5); the interaction between saturated fat and lignan intake was statistically significant for high risk adenoma recurrence $(P=0.01)$ but not for any adenoma recurrence $(P=0.32)$. The effect modification was not statistically significant for fibre (data not shown). Total proanthocyanidin intake was positively associated with any adenoma recurrence in individuals with a saturated fat intake equal or below the median ( $\mathrm{OR}=1.53$, $95 \% \mathrm{CI}=0.95-2.46, P$ trend $=0.05$; Table 5).

\section{Discussion}

The objective of this study was to prospectively examine the association between consumption of lignans and proanthocyanidins and colorectal adenoma recurrence. Overall, dietary lignan and proanthocyanidin intake was not associated with colorectal adenoma recurrence. However, when stratified by gender, high lignan intake was associated with an increased risk of any adenoma recurrence in women. Furthermore, high lignan intake was associated with an increased risk of any and high risk adenoma recurrence in individuals that consumed saturated fat at or below the median intake level. Our results suggest that high lignan intake may increase the risk of adenoma recurrence in women and individuals with low saturated fat intake.

The association between lignans and their metabolites enterolactone and enterodiol in plasma and colorectal neoplasia has been mixed in human studies. In a Canadian casecontrol study, lignan consumption was inversely associated with colorectal cancer ${ }^{39}$. Similarly, in a Dutch endoscopy-based case-control study, plasma enterodiol, but not enterolactone, concentrations were inversely associated with incident colorectal adenoma risk ${ }^{40}$. However, the authors could not reproduce the inverse relationship between enterodiol and colorectal cancer risk in a subsequent nested case-control study ${ }^{41}$. Moreover, they reported, similar to our findings, a gender specific increased risk of colorectal cancer with high enterolactone concentrations in women ${ }^{41}$. In contrast, both Danish and English nested case-control studies reported that high plasma enterolactone concentrations decreased the risk of colorectal cancer in women ${ }^{18,19}$; however, similar to our results, lignan consumption tended to be associated with increased colorectal cancer risk in the English study ${ }^{18}$.

Dietary lignan sources partly explain the mixed results across different studies; for example, $88 \%$ of dietary lignans were from flaxseed in the Canadian study ${ }^{11}$, a food item that was rarely consumed in the 1990s in the U.S. Flaxseed is not only a good dietary source of lignans but also of omega- 3 fatty acids, which may protect against colorectal tumorigenesis. In addition, diet composition, specifically dietary fiber and lipids, may impact the metabolism of plant lignans to the more bioactive enterolactone and enterodiol and, therefore the association between dietary lignans and colorectal carcinogenesis ${ }^{18,20}$. For 
example, lipid consumption (in particular the consumption of saturated fats) decreases the conversion of dietary plant lignans to enterolignans 6,20 ; thus, enterolignan concentrations may be higher in individuals with a low saturated fat intake, which may partly explain why the detrimental effect of high lignan consumption on adenoma recurrence can only be observed in the low saturated fat intake group. Alternatively, the lignan to lipid ratio may influence cancer risk because lignans and lipids both alter the metabolism of steroid hormones 6,21 , which are involved in the etiology of colorectal tumorigenesis. Dietary lipids may modify the effect of dietary fibre, which is closely associated with lignan consumption 6,20 , on colorectal carcinogenesis, as has been demonstrated in animal models ${ }^{42-44}$. The gender difference in risk of colorectal neoplasms observed in this and other studies $18,19,41$, may be related to the ability of lignans to bind to estrogen receptors and thereby antagonizing endogenously synthesized estrogen $6,18,21$ but there is some evidence to suggest that this may also increase proliferation of colonic epithelial cells 2,45 .

The number of human studies that have investigated the association between proanthocyanidin consumption and risk of colorectal neoplasms is limited. A Scottish and an Italian case-control study reported an inverse association between proanthocyanidin intake and colorectal cancer risk ${ }^{29,30}$. In contrast, a second Scottish case-control study, as well as the prospective Iowa Women's Health Study detected no association with colorectal cancer ${ }^{31,32}$, which is similar to our results. Variation in dietary proanthocyanidin sources (apples and tea in most studies), may partly explain differences in associations. We previously reported that increasing dry bean intake reduced the risk of advanced adenoma recurrence in the PPT ${ }^{46}$. Although proanthocyanidins have been considered for prevention and therapy of cancer ${ }^{28}$, high proanthocyanidin intake has risks and potentially procarcinogenic effects. Proanthocyanidins can inhibit the growth of the intestinal microbial flora, chelate minerals and thereby decrease their absorption, inhibit intestinal enzymes, and are toxic at high concentrations 2,45 . Other dietary components may also influence the association between proanthocyanidins, especially for polymeric proanthocyanidins, and cancer risk, as only monomeric, dimeric, or trimeric proanthocyanidins are absorbed ${ }^{27}$. This is, to our knowledge, the first study to examine the association between consumption of proanthocyanidins and risk of colorectal adenomas. The association between consumption of proanthoycyanidins and risk of colorectal cancer may vary from the association with colorectal adenomas.

Strengths of our study include the prospective, annual collection of dietary data and the use of a questionnaire that was specifically designed to accurately estimate consumption of fibre, fruit, and vegetables ${ }^{34,35}$. The immediate review of all questionnaires by registered dieticians further improved the accuracy of dietary data ${ }^{36}$, and validated proanthocyanidin and lignan databases were used to estimate proanthocyanidin and lignan intake $8,10,26,37,38$. Another major strength was the complete outcome surveillance, which included colonoscopies at baseline and at the end of T1 and T4 and independent, histological characterization of all colorectal lesions by two pathologists, which minimized outcome misclassification.

Limitations of this study include that the FFQ did not specifically ask about intake of sesame and flax seed, which are enriched in lignans and have shown a protective effect in Canadian studies $8,11,39$. The use of sesame and flax seed in the U.S. was low in the 1990s; thus, we cannot exclude the possibility that at higher intake levels, the associations might be different. In addition, the FFQ was not specifically developed and validated for estimating proanthocyanidin and lignan intake and several databases were used to estimate lignan intake; however, 58 of 65 food and beverage items were estimated from a single lignan database. These results from the PPT population, which had a history of adenomas, were nearly exclusively Caucasians engaged in a relatively healthy lifestyle, and had a 
comparably low lignan intake ( $167 \mu \mathrm{g} / \mathrm{d})$ compared to the European and Canadian studies $(200-1000 \mu \mathrm{g} / \mathrm{d}){ }^{18,20,39}$, may be limited in their generalizability. Use of dietary supplements rich in proanthocyanidins and lignans was low in the PPT and, thus, not included in the intake estimation, which may cause random and systematic misclassification of proanthocyanidin and lignan consumption ${ }^{47}$. Other potential sources of random and systematic misclassification relate to dietary assessment technique, proanthocyanidin and lignan databases, variations in food quantities of recipes or grouped foods, variability in lignan and proanthocyanidin content due to climatic, growing, soil, and harvesting conditions of plants and storage and preparation conditions of foods. Furthermore, participants were aware of the expected dietary patterns and in $12 \%$ of participants $\mathrm{T} 3$ dietary data were obtained before an unscheduled colonoscopy used for assessing adenoma recurrence.

There might be concerns regarding the size of the population; however, a Monte-Carlo study indicated that we would have $99 \%$ and $96 \%$ power to detect small to moderate sized main effects for any recurrence and for an advanced recurrence, respectively. Observed differences might have arisen by chance because this is a secondary analysis, which included stratification into subgroups, and participants were not specifically assigned to a lignan or proanthocyanidin rich diet. However, the monotonic increase in ORs for adenoma recurrence with lignan intake in women and individuals that consumed saturated fat below or equal $18.3 \mathrm{~g} / \mathrm{d}$ in combination with the biological plausibility for such an association is unlikely due to chance and supports the assertion that, despite potential dietary measurement error, the study had sufficient statistical power and participants were ranked robustly enough to observe an association.

\section{Conclusion}

In conclusion, consumption of lignans or proanthocyanidins was not associated with colorectal adenoma recurrence overall. However, high lignan intake may increase the risk of any adenoma recurrence in women and in individuals with saturated fat intake below or equal $18.3 \mathrm{~g} / \mathrm{d}$, which suggests gender and dietary fat may modify this association. Further studies are needed to examine the importance and biological role of lignans and proanthocyanidins in colorectal carcinogenesis.

\section{Acknowledgments}

We would like to thank the Polyp Prevention Trial Study Group for their outstanding contribution to this project.

Funding: This study was funded by the Intramural Research Program, National Cancer Institute, NIH, DHHS, Bethesda, MD.

\section{Abbreviations used}

$\begin{array}{ll}\text { BMI } & \text { body mass index } \\ \text { CI } & \text { confidence interval } \\ \text { EGCG } & \text { epigallocatechin 3-gallate } \\ \text { FFQ } & \text { food frequency questionnaire } \\ \text { IQR } & \text { interquartile range } \\ \text { NSAID } & \text { nonsteroidal anti-inflammatory drug } \\ \text { OR } & \text { odds ratio }\end{array}$



PPT
Polyp Prevention Trial
USDA
U.S. Department of Agriculture

\section{References}

1. Fresco P, Borges F, Diniz C, Marques MP. New insights on the anticancer properties of dietary polyphenols. Med Res Rev. 2006; 26:747-66. [PubMed: 16710860]

2. Scalbert A, Manach C, Morand C, Remesy C, Jimenez L. Dietary polyphenols and the prevention of diseases. Crit Rev Food Sci Nutr. 2005; 45:287-306. [PubMed: 16047496]

3. Bravo L. Polyphenols: chemistry, dietary sources, metabolism, and nutritional significance. Nutr Rev. 1998; 56:317-33. [PubMed: 9838798]

4. Bobe G, Sansbury LB, Albert PS, Cross AJ, Kahle L, Ashby J, Slattery ML, Caan B, Paskett E, Iber F, Kikendall JW, Lance P, et al. Dietary flavonoids and colorectal adenoma recurrence in the Polyp Prevention Trial. Cancer Epidemiol Biomarkers Prev. 2008; 17:1344-53. [PubMed: 18559549]

5. Bobe G, Albert PS, Sansbury LB, Lanza E, Schatzkin A, Colburn NH, Cross AJ. Interleukin-6 as a potential indicator for prevention of high-risk adenoma recurrence by dietary flavonols in the polyp prevention trial. Cancer Prev Res (Phila Pa). 2010; 3:764-75.

6. Adlercreutz H. Lignans and human health. Crit Rev Clin Lab Sci. 2007; 44:483-525. [PubMed: 17943494]

7. Lund TD, West TW, Tian LY, Bu LH, Simmons DL, Setchell KD, Adlercreutz H, Lephart ED. Visual spatial memory is enhanced in female rats (but inhibited in males) by dietary soy phytoestrogens. BMC Neurosci. 2001; 2:20. [PubMed: 11801187]

8. Thompson LU, Boucher BA, Liu Z, Cotterchio M, Kreiger N. Phytoestrogen content of foods consumed in Canada, including isoflavones, lignans, and coumestan. Nutr Cancer. 2006; 54:184201. [PubMed: 16898863]

9. Horn-Ross PL, Lee M, John EM, Koo J. Sources of phytoestrogen exposure among non-Asian women in California, USA. Cancer Causes Control. 2000; 11:299-302. [PubMed: 10843441]

10. de Kleijn MJ, van der Schouw YT, Wilson PW, Adlercreutz H, Mazur W, Grobbee DE, Jacques PF. Intake of dietary phytoestrogens is low in postmenopausal women in the United States: the Framingham study(1-4). J Nutr. 2001; 131:1826-32. [PubMed: 11385074]

11. Cotterchio M, Boucher BA, Kreiger N, Mills CA, Thompson LU. Dietary phytoestrogen intake-lignans and isoflavones--and breast cancer risk (Canada). Cancer Causes Control. 2008; 19:259_ 72. [PubMed: 17992574]

12. Miura D, Saarinen NM, Miura Y, Santti R, Yagasaki K. Hydroxymatairesinol and its mammalian metabolite enterolactone reduce the growth and metastasis of subcutaneous AH109A hepatomas in rats. Nutr Cancer. 2007; 58:49-59. [PubMed: 17571967]

13. Chen J, Thompson LU. Lignans and tamoxifen, alone or in combination, reduce human breast cancer cell adhesion, invasion and migration in vitro. Breast Cancer Res Treat. 2003; 80:163-70. [PubMed: 12908819]

14. Qu H, Madl RL, Takemoto DJ, Baybutt RC, Wang W. Lignans are involved in the antitumor activity of wheat bran in colon cancer SW480 cells. J Nutr. 2005; 135:598-602. [PubMed: 15735100]

15. Danbara N, Yuri T, Tsujita-Kyutoku M, Tsukamoto R, Uehara N, Tsubura A. Enterolactone induces apoptosis and inhibits growth of Colo 201 human colon cancer cells both in vitro and in vivo. Anticancer Res. 2005; 25:2269-76. [PubMed: 16158974]

16. Sung MK, Lautens M, Thompson LU. Mammalian lignans inhibit the growth of estrogenindependent human colon tumor cells. Anticancer Res. 1998; 18:1405-8. [PubMed: 9673348]

17. Hu C, Yuan YV, Kitts DD. Antioxidant activities of the flaxseed lignan secoisolariciresinol diglucoside, its aglycone secoisolariciresinol and the mammalian lignans enterodiol and enterolactone in vitro. Food Chem Toxicol. 2007; 45:2219-27. [PubMed: 17624649]

18. Ward HA, Kuhnle GG, Mulligan AA, Lentjes MA, Luben RN, Khaw KT. Breast, colorectal, and prostate cancer risk in the European Prospective Investigation into Cancer and Nutrition-Norfolk 
in relation to phytoestrogen intake derived from an improved database. Am J Clin Nutr. 2010; 91:440-8. [PubMed: 20007303]

19. Johnsen NF, Olsen A, Thomsen BL, Christensen J, Egeberg R, Knudsen KE Bach, Loft S, Overvad $\mathrm{K}$, Tjonneland A. Plasma enterolactone and risk of colon and rectal cancer in a case-cohort study of Danish men and women. Cancer Causes Control. 2010; 21:153-62. [PubMed: 19844797]

20. Milder IE, Kuijsten A, Arts IC, Feskens EJ, Kampman E, Hollman PC, Van 't Veer P. Relation between plasma enterodiol and enterolactone and dietary intake of lignans in a Dutch endoscopybased population. J Nutr. 2007; 137:1266-71. [PubMed: 17449591]

21. Barone M, Tanzi S, Lofano K, Scavo MP, Guido R, Demarinis L, Principi MB, Bucci A, Di Leo A. Estrogens, phytoestrogens and colorectal neoproliferative lesions. Genes Nutr. 2008; 3:7-13. [PubMed: 18850193]

22. Prior RL, Gu L. Occurrence and biological significance of proanthocyanidins in the American diet. Phytochemistry. 2005; 66:2264-80. [PubMed: 15904940]

23. Gu L, Kelm MA, Hammerstone JF, Beecher G, Holden J, Haytowitz D, Gebhardt S, Prior RL. Concentrations of proanthocyanidins in common foods and estimations of normal consumption. $\mathrm{J}$ Nutr. 2004; 134:613-7. [PubMed: 14988456]

24. Cos P, De Bruyne T, Hermans N, Apers S, Berghe DV, Vlietinck AJ. Proanthocyanidins in health care: current and new trends. Curr Med Chem. 2004; 11:1345-59. [PubMed: 15134524]

25. Ovaskainen ML, Torronen R, Koponen JM, Sinkko H, Hellstrom J, Reinivuo H, Mattila P. Dietary intake and major food sources of polyphenols in Finnish adults. J Nutr. 2008; 138:562-6. [PubMed: 18287367]

26. U.S. Department of Agriculture ARS. USDA Database for the proanthocyanidin content of selected foods Nutrient Data Laboratory web site. ed. 2004. USDA; 2004.

27. Serrano J, Puupponen-Pimia R, Dauer A, Aura AM, Saura-Calixto F. Tannins: current knowledge of food sources, intake, bioavailability and biological effects. Mol Nutr Food Res. 2009; 53(Suppl 2):S310-29. [PubMed: 19437486]

28. Nandakumar V, Singh T, Katiyar SK. Multi-targeted prevention and therapy of cancer by proanthocyanidins. Cancer Lett. 2008; 269:378-87. [PubMed: 18457915]

29. Theodoratou E, Kyle J, Cetnarskyj R, Farrington SM, Tenesa A, Barnetson R, Porteous M, Dunlop M, Campbell H. Dietary flavonoids and the risk of colorectal cancer. Cancer Epidemiol Biomarkers Prev. 2007; 16:684-93. [PubMed: 17416758]

30. Rossi M, Negri E, Parpinel M, Lagiou P, Bosetti C, Talamini R, Montella M, Giacosa A, Franceschi S, La Vecchia C. Proanthocyanidins and the risk of colorectal cancer in Italy. Cancer Causes Control. 2010; 21:243-50. [PubMed: 20012183]

31. Cutler GJ, Nettleton JA, Ross JA, Harnack LJ, Jacobs DR Jr. Scrafford CG, Barraj LM, Mink PJ, Robien K. Dietary flavonoid intake and risk of cancer in postmenopausal women: the Iowa Women's Health Study. Int J Cancer. 2008; 123:664-71. [PubMed: 18491403]

32. Kyle JA, Sharp L, Little J, Duthie GG, McNeill G. Dietary flavonoid intake and colorectal cancer: a case-control study. Br J Nutr. 2010; 103:429-36. [PubMed: 19732470]

33. Schatzkin A, Lanza E, Corle D, Lance P, Iber F, Caan B, Shike M, Weissfeld J, Burt R, Cooper MR, Kikendall JW, Cahill J. Lack of effect of a low-fat, high-fiber diet on the recurrence of colorectal adenomas. Polyp Prevention Trial Study Group. N Engl J Med. 2000; 342:1149-55. [PubMed: 10770979]

34. Lanza E, Schatzkin A, Daston C, Corle D, Freedman L, Ballard-Barbash R, Caan B, Lance P, Marshall J, Iber F, Shike M, Weissfeld J, et al. Implementation of a 4-y, high-fiber, high-fruit-andvegetable, low-fat dietary intervention: results of dietary changes in the Polyp Prevention Trial. Am J Clin Nutr. 2001; 74:387-401. [PubMed: 11522565]

35. Lanza E, Schatzkin A, Ballard-Barbash R, Corle D, Clifford C, Paskett E, Hayes D, Bote E, Caan B, Shike M, Weissfeld J, Slattery M, et al. The polyp prevention trial II: dietary intervention program and participant baseline dietary characteristics. Cancer Epidemiol Biomarkers Prev. 1996; 5:385-92. [PubMed: 9162305]

36. Caan BJ, Lanza E, Schatzkin A, Coates AO, Brewer BK, Slattery ML, Marshall JR, Bloch A. Does nutritionist review of a self-administered food frequency questionnaire improve data quality? Public Health Nutr. 1999; 2:565-9. [PubMed: 10656476] 
37. Boker LK, Van der Schouw YT, De Kleijn MJ, Jacques PF, Grobbee DE, Peeters PH. Intake of dietary phytoestrogens by Dutch women. J Nutr. 2002; 132:1319-28. [PubMed: 12042453]

38. Milder IE, Arts IC, van de Putte B, Venema DP, Hollman PC. Lignan contents of Dutch plant foods: a database including lariciresinol, pinoresinol, secoisolariciresinol and matairesinol. $\mathrm{Br} \mathrm{J}$ Nutr. 2005; 93:393-402. [PubMed: 15877880]

39. Cotterchio M, Boucher BA, Manno M, Gallinger S, Okey A, Harper P. Dietary phytoestrogen intake is associated with reduced colorectal cancer risk. J Nutr. 2006; 136:3046-53. [PubMed: 17116718]

40. Kuijsten A, Arts IC, Hollman PC, van't Veer P, Kampman E. Plasma enterolignans are associated with lower colorectal adenoma risk. Cancer Epidemiol Biomarkers Prev. 2006; 15:1132-6. [PubMed: 16775171]

41. Kuijsten A, Hollman PC, Boshuizen HC, Buijsman MN, van 't Veer P, Kok FJ, Arts IC, Bueno-deMesquita HB. Plasma enterolignan concentrations and colorectal cancer risk in a nested casecontrol study. Am J Epidemiol. 2008; 167:734-42. [PubMed: 18192676]

42. Lee DY, Chapkin RS, Lupton JR. Dietary fat and fiber modulate colonic cell proliferation in an interactive site-specific manner. Nutr Cancer. 1993; 20:107-18. [PubMed: 8233976]

43. Whiteley LO, Purdon MP, Ridder GM, Bertram TA. The interactions of diet and colonic microflora in regulating colonic mucosal growth. Toxicol Pathol. 1996; 24:305-14. [PubMed: 8736386]

44. Crim KC, Sanders LM, Hong MY, Taddeo SS, Turner ND, Chapkin RS, Lupton JR. Upregulation of $\mathrm{p} 21 \mathrm{Waf} 1 / \mathrm{Cip} 1$ expression in vivo by butyrate administration can be chemoprotective or chemopromotive depending on the lipid component of the diet. Carcinogenesis. 2008; 29:1415-20. [PubMed: 18567619]

45. Mennen LI, Walker R, Bennetau-Pelissero C, Scalbert A. Risks and safety of polyphenol consumption. Am J Clin Nutr. 2005; 81:326S-9S. [PubMed: 15640498]

46. Lanza E, Hartman TJ, Albert PS, Shields R, Slattery M, Caan B, Paskett E, Iber F, Kikendall JW, Lance P, Daston C, Schatzkin A. High dry bean intake and reduced risk of advanced colorectal adenoma recurrence among participants in the polyp prevention trial. J Nutr. 2006; 136:1896-903. [PubMed: 16772456]

47. Thompson LU, Boucher BA, Cotterchio M, Kreiger N, Liu Z. Dietary phytoestrogens, including isoflavones, lignans, and coumestrol, in nonvitamin, nonmineral supplements commonly consumed by women in Canada. Nutr Cancer. 2007; 59:176-84. [PubMed: 18001212] 


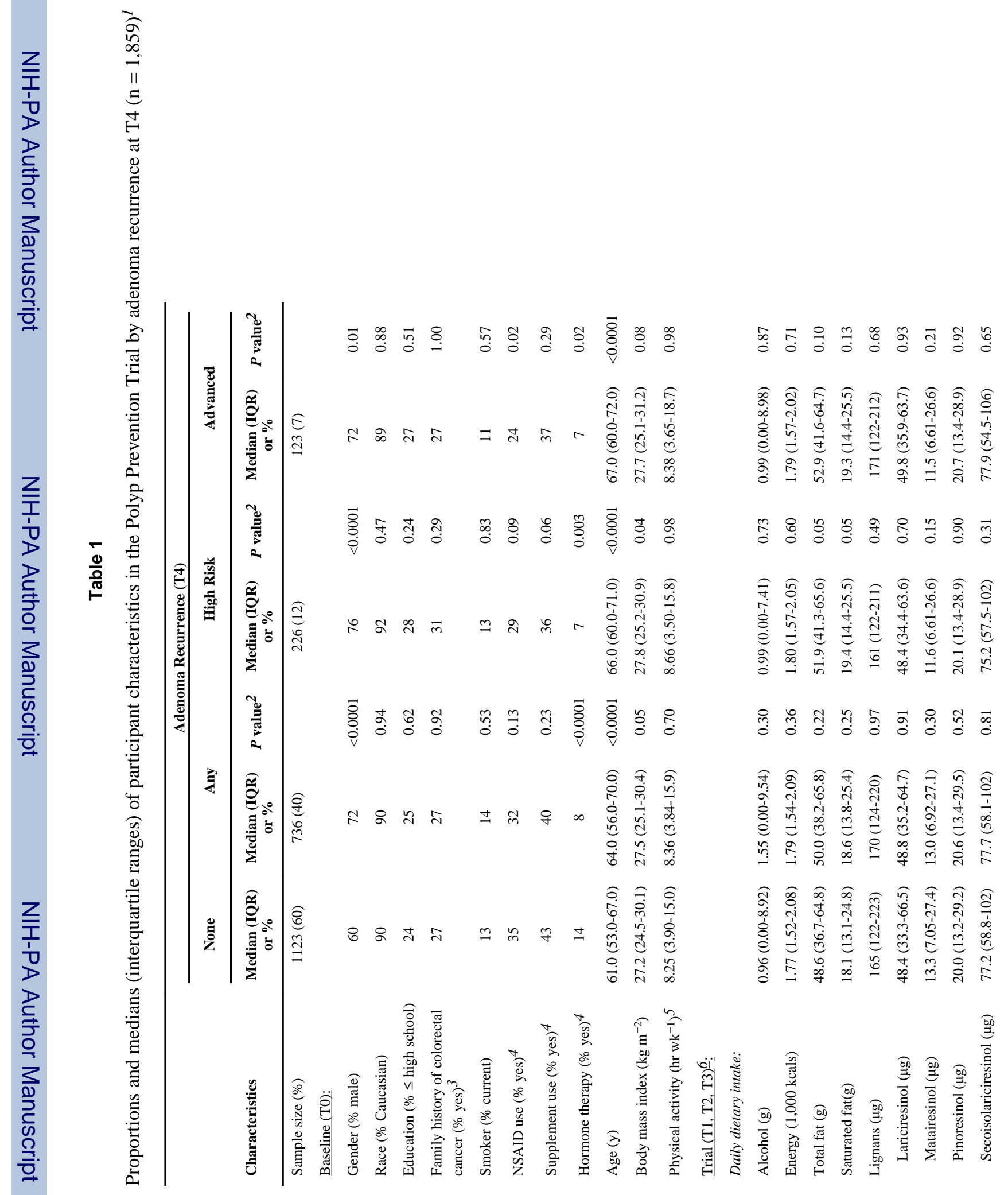




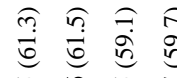

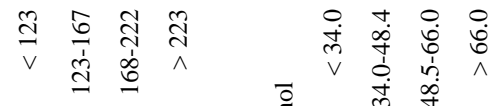

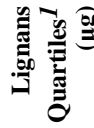




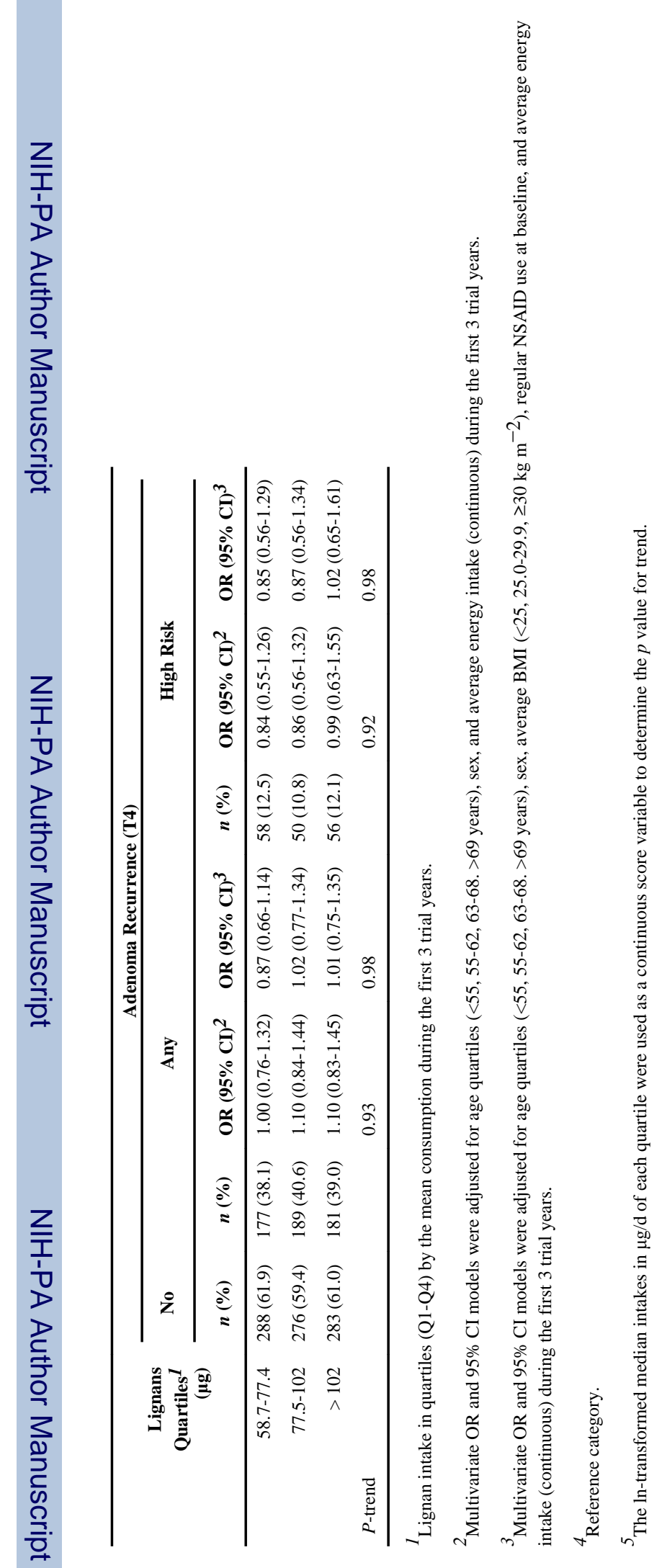




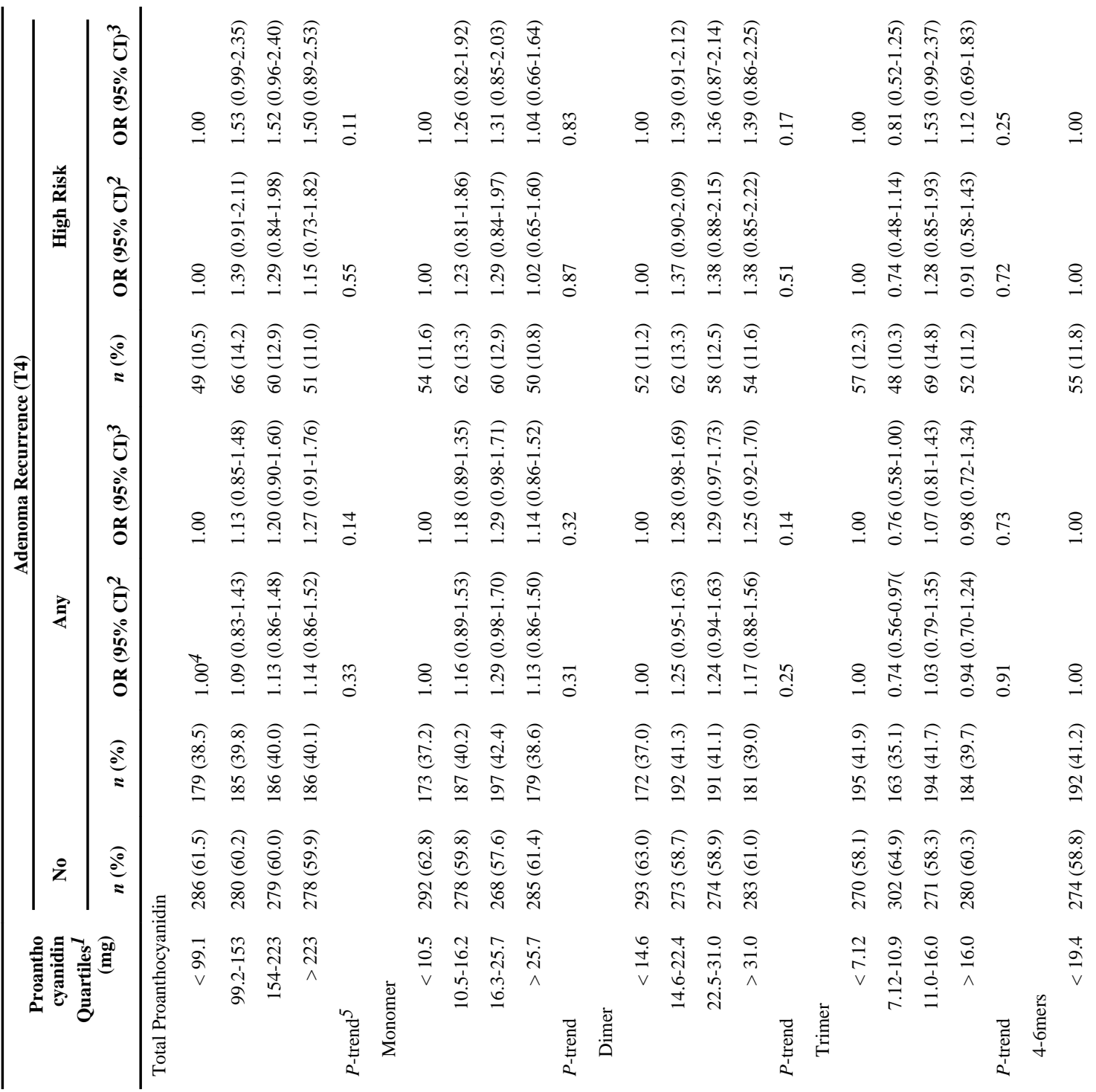




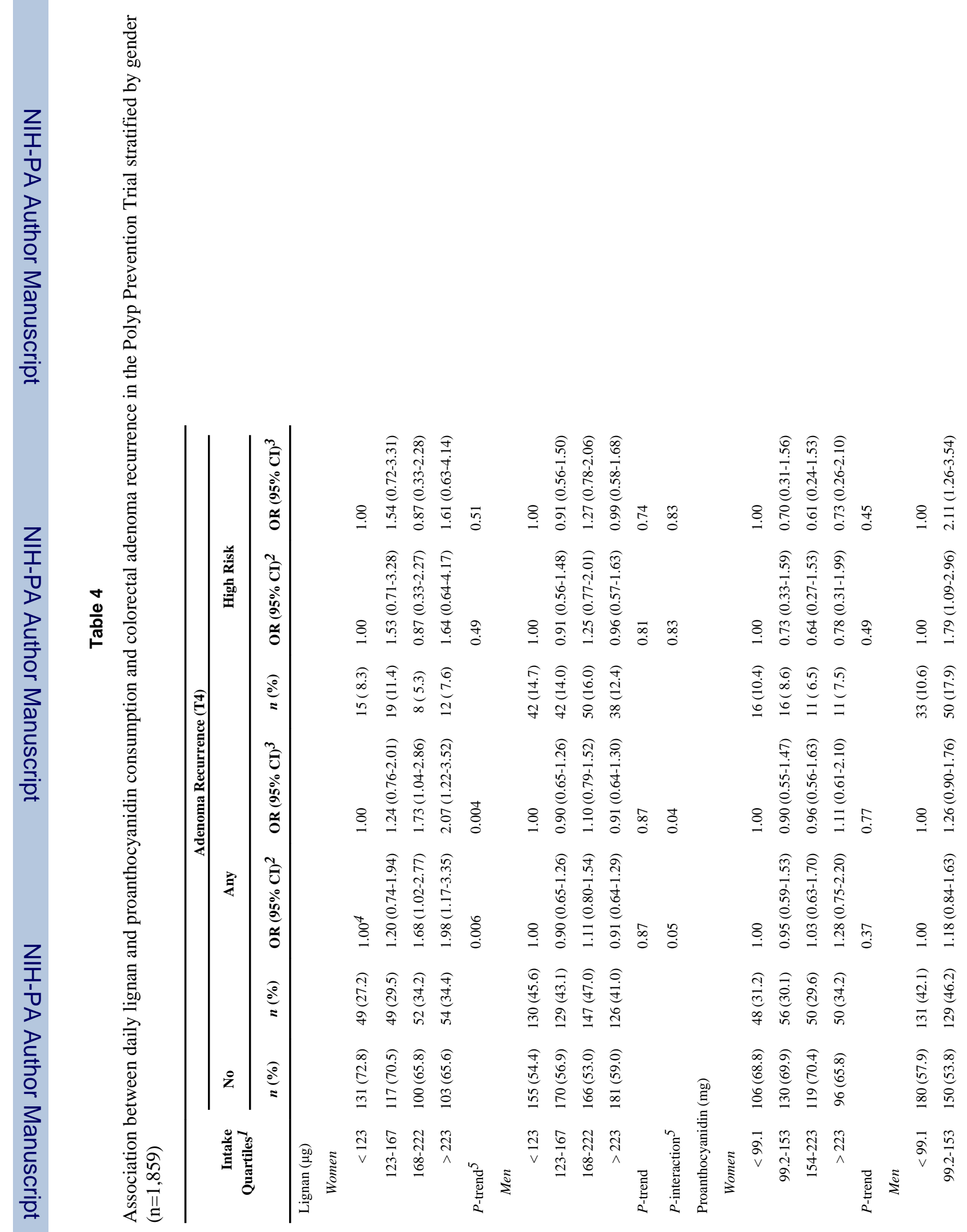




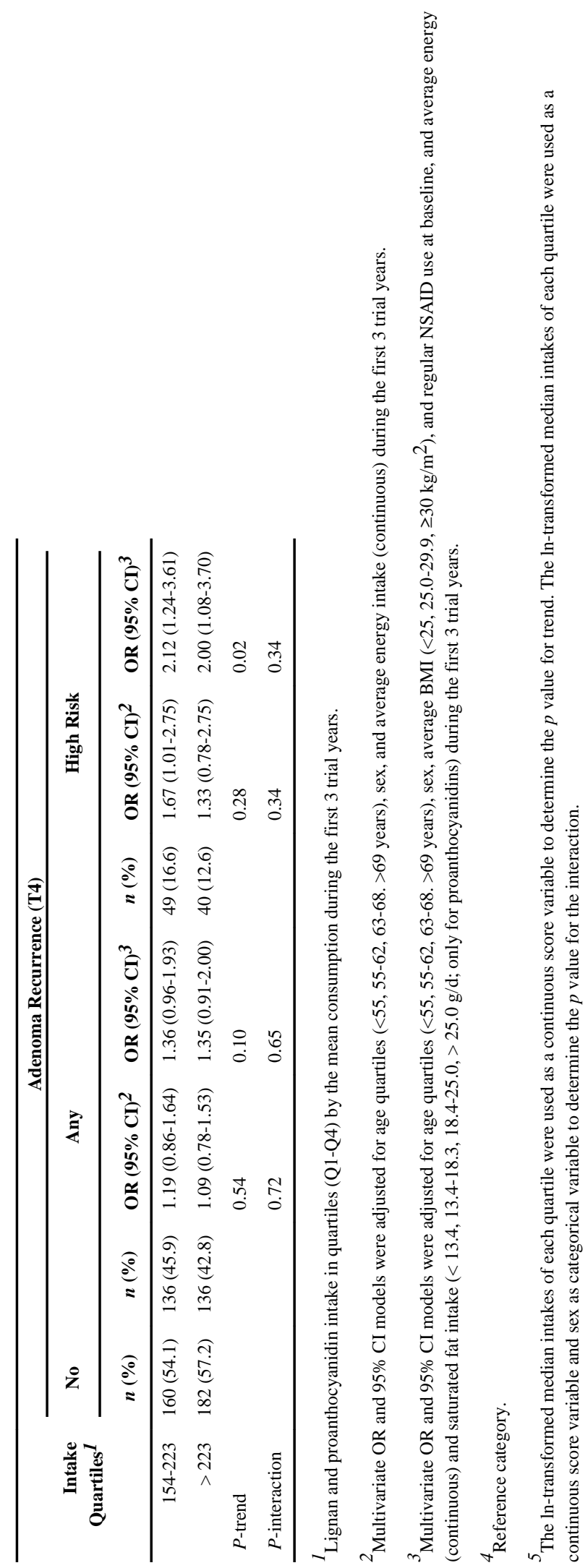




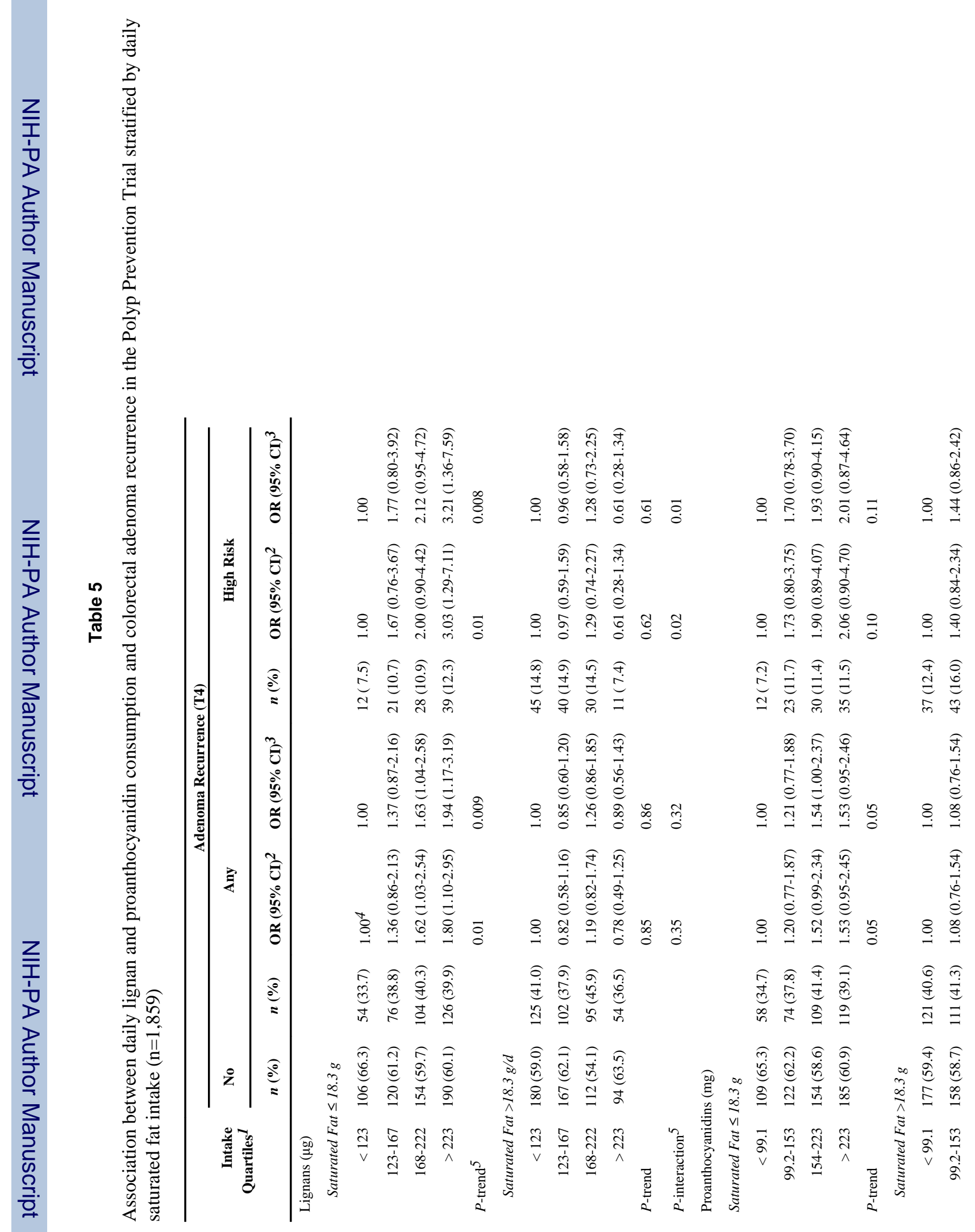




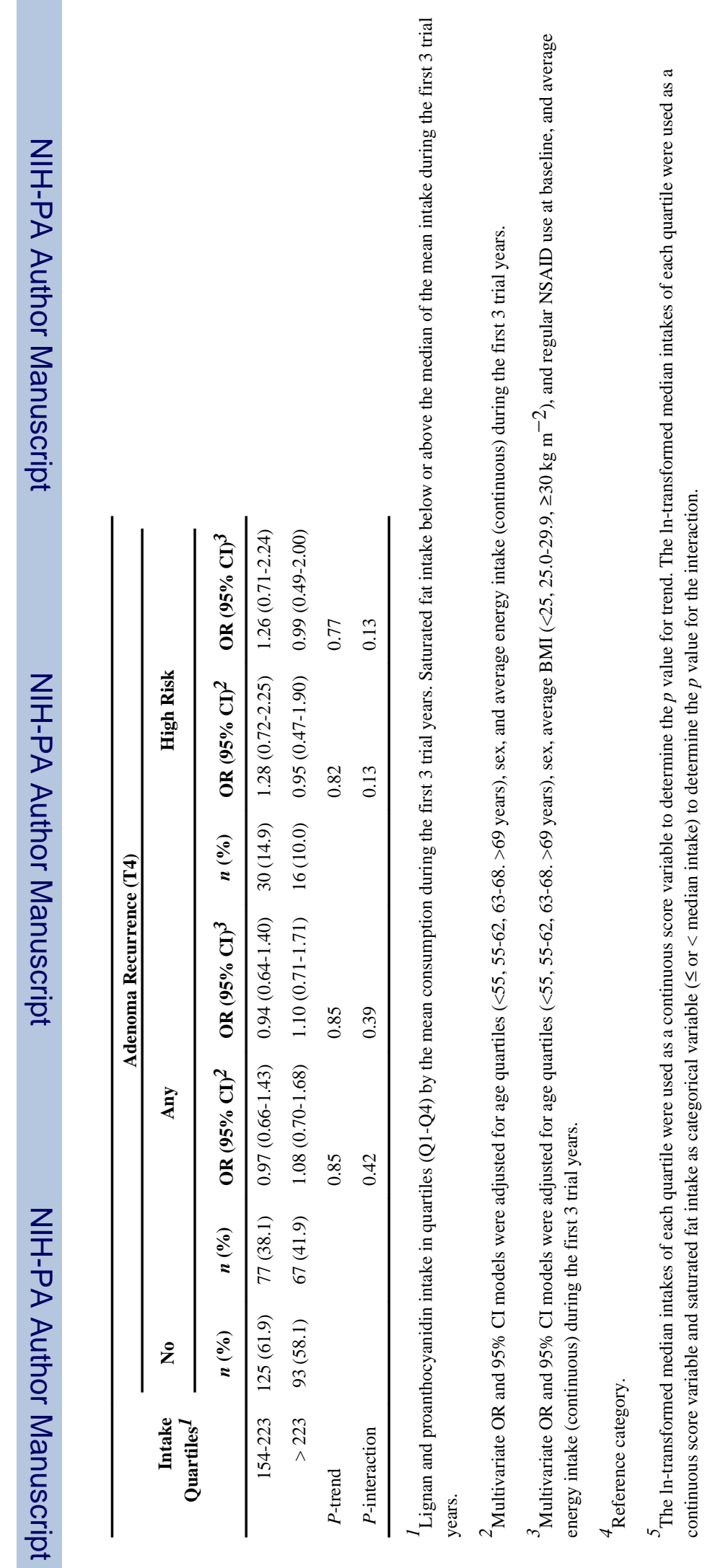

